\title{
Mechanisms of Nitramine Thermolysis ${ }^{1}$
}

\author{
J.C. Oxley*; A.B. Kooh; R. Szekeres; W. Zheng \\ Chemistry Department \\ New Mexico Institute of Mining \& Technology \\ Socorro, New Mexico 87801
}

\begin{abstract}
The thermal decomposition of a number of nitramines was studied in dilute solution and in the melt. The nitramines included acyclic mononitramines [dimethylnitramine (DMN), diethylnitramine (DEN), dipropylnitramine (DPN), and diisopropylnitramine (DIPN)], cyclic mononitramines [N-nitro-piperidine (NPIP) and N-nitropyrrolidine (NPyr)], cyclic dinitramines [N-dinitropiperazine (pDNP), 1,3-dinitro-1,3-diazacyclopentane (DNI), and 1,3-dinitro-1,3diazacyclohexane (mDNP)], and 1,3,5-trinitro-1,3,5-triazocyclohexane (RDX), octahydro-1,3,5,7tetranitro-1,3,5,7-tetrazocine(HMX), hexanitro-hexaazaisowurtzitane (HNIW), and 1,3,3trinitroazetidine (TNAZ). For the acyclic and cyclic mono- and di-nitramines, the corresponding nitrosamines were the only or major condensed-phase product.
\end{abstract}

Kinetics and activation parameters were determined for the thermolysis of dilute solutions ( 0.01 to $1.0 \mathrm{wt} \%$ ) over range $200^{\circ}$ to $300^{\circ} \mathrm{C}$. The thermolyses were found to be first-order with the rate constants unaffected by use of deuterated solvent. As the nitramines became more complex than dimethylnitramine $(\mathrm{DMN})$, the rate of decomposition increased and the product distribution became more complex. As the length of the aliphatic chain increased (DMN $<$ DEN $<$ DPN), the rate of thermolysis increased, yet nitrosamine remained the only observed condensed-phase product. When a secondary carbon was attached to the N-nitramine (DIPN) rather than primary (DPN), the rate of decomposition increased and a new condensed-phase product was observed. Among the cyclic nitramines, the rate of decomposition increased as the number of $\mathrm{NNO}_{2}$ groups increased (NPIP $<$ pDNP; NPyr $<$ DNI; mDMP $<$ RDX). The position of the nitramine groups affected the decomposition; meta $\mathrm{NNO}_{2}$ groups (mDNP) decomposed faster than para (pDNP). Ring strain decreased stability: $\mathrm{mDNP}<\mathrm{DNI}$; HMX $<\mathrm{RDX}$. In complex nitramines, the increase in decomposition rate, the appearance of new products, and the change in the relative importance of nitrosamine and of $\mathrm{N}_{2}$ and $\mathrm{N}_{2} \mathrm{O}$ is attributed to new decomposition routes available to them. However, since complex nitramines (e.g. RDX) maintain first-order kinetics and since most have activation energies in the range of 40 to $50 \mathrm{kcal} / \mathrm{mol}$, it is believed that the triggering mechanism remains $\mathrm{N}-\mathrm{NO}_{2}$ homolysis. Intramolecular hydrogen transfer is also considered an important mode of nitramine decomposition.

\section{Introduction}

Before attempting to understand the mechanisms operating in species containing multiple nitramine functionalities, we examined the simple nitramine, dimethylnitramine (DMN). ${ }^{2}$ To avoid complications resulting from multiphase decomposition and autocatalysis, ${ }^{3,4}$ we studied the thermolysis in dilute solution. Two different ${ }^{15} \mathrm{~N}$-labeling studies were performed. In both, complete label scrambling was observed in the $\mathrm{N}_{2}$ and $\mathrm{N}_{2} \mathrm{O}$ gases and in the dimethylnitrosamine. Only partial scrambling of the ${ }^{15} \mathrm{~N}$-label was observed in the reactant, DMN. ${ }^{2}$ Kinetic studies of 
DMN, diisopropylnitramine (DIPN), and N-nitropiperidine (NPIP) showed that as the viscosity of the solvent increased, the rate of decomposition decreased. This solvent cage effect and the observations of a large positive activation volume $\left(\mathrm{V}^{*}=+30\right)$ for DMN suggested that the ratedetermining step was homolysis, the $\mathrm{N}-\mathrm{NO}_{2}$ bond being the most obvious point. A deuterium kinetic isotope effect (DKIE) was observed in the decomposition of DMN and its deuterated analog, implying that internal hydrogen transfer was involved in the rate-determining step. Acidic and basic species and free-radical scavengers appeared to have no effect on the rate of DMN decomposition, either in the neat melt or in solution. From the above results, two decomposition routes were postulated for DMN: hydrogen transfer from the methyl group in the nitramine to its $\mathrm{NO}_{2}$ group resulting in loss of $\mathrm{HONO}$; and $\mathrm{N}-\mathrm{NO}_{2}$ homolysis. ${ }^{2}$ The first route would be first order and explain the ${ }^{15} \mathrm{~N}$ label scrambling in the nitrogen gases and the internal DKIE. The second would be a first-order route to nitrosamine and would explain the solvent cage effect and positive activation volume.

In the present studies, we compare the thermal decomposition of dimethylnitramine to a number of more complex nitramines--both acyclic, cyclic and polycyclic. Primarily thermolyses have been performed in solution, using the solvent as a possible radical trap for intermediates and also as a diluent to discourage autocatalysis. The mechanism of decomposition was deduced from observed reaction kinetics and decomposition products.

\section{Experimental Section}

Dimethylnitramine (DMN), ${ }^{15} \mathrm{~N}$-labeled DMN, and N-nitropyrrolidine were prepared by dehydration of the corresponding dialkylammonium nitrate salt. ${ }^{5}$ Perdeutero-dimethylnitramine was prepared from perdeutero-dimethylformamide by the method of Robson. ${ }^{6}$ Diisopropyl-, diethyl-, and dipropyl-nitramine, N-nitropiperidine, and dinitropiperazine were formed by treatment of the corresponding amine with dinitrogen pentoxide. ${ }^{7,8}$ 1,3-Dinitro-1,3diazacyclopentane and 1,3-dinitro-1,3-diazacyclohexane were formed by condensation of the appropriate dinitramine with formaldehyde. ${ }^{9}$ RDX, HMX, TNAZ, and HNIW were supplied by various government laboratories. Dimethylnitrosamine and diisopropylnitrosamine were prepared by adding the corresponding amines to a cold aqueous solution of sodium nitrite, which had been acidified with hydrochloric acid. ${ }^{10}$ The mono-nitroso analog of RDX was prepared by the method of Bell and Dunstan and recrystallized by published procedures. ${ }^{11,12}$ The di- and tri-nitroso analogues of RDX were synthesized following the procedure outlined by Hoffsommer and references therein. ${ }^{13}$

Isothermal decompositions of the nitramines were conducted in sealed glass tubes as previously discussed. ${ }^{2}$ Typically, samples were benzene, isooctane, or acetone solutions containing 0.1-1.0 wt $\%$ nitramine ( $\mathrm{N}$-nitropiperidine was $10 \mathrm{wt} \%$ in benzene). Thermolyses were performed isothermally in the temperature range $200^{\circ} \mathrm{C}$ to $300^{\circ} \mathrm{C}$, with the bath temperature maintained within $1{ }^{\circ} \mathrm{C}$ of the desired temperature. To examine the condensed and vapor phase thermolyses, about 0.2 $\mathrm{mg}$ of the desired nitramine was sealed into the glass thermolysis tube. To promote vapor phase decomposition, the tubes were evacuated. To determine energy of activation (Table I), solution rate constants were determined for at least five temperatures. Rate constants at as few as three temperatures were used for condensed phase activation energy calculations. For comparative purposes, only the rate constants at $240^{\circ} \mathrm{C}$ are listed in Table I. 
The thermolysis products were analyzed by a Hewlett-Packard 5890A gas chromatograph (GC) equipped with a 5970B quadrupole mass-selective detector (MS) and a narrow-bore HP-1 (crosslinked methylsilicone) capillary column (25 m x .20 mm I.D.). Identification of a mass spectrum was achieved by comparing the mass spectrum to that of an authentic sample or by interpretation of the fragmentation pattern. Gaseous products were separated and quantitatively identified using a Varian 3600 gas chromatograph equipped with a thermal conductivity detector (GC-TCD). ${ }^{2} \quad$ The GC was configured with a PORAPAK-Q column in series across the TCD detector with a molecular sieve (MS13X) column. Identification and quantification of the gases was achieved by comparing the retention times and areas to calibration curves of known gases.

The method in which fraction of unreacted nitramine was quantified depended on the properties of each species. For many, a gas chromatograph (GC, Varian 3600) equipped with capillary column (DB-05) and flame ionization detector was used (helium flow rate, $30 \mathrm{~mL} / \mathrm{min}$ ).

For others, a high-performance liquid chromatograph equipped (HPLC) with a $20 \mathrm{uL}$ sample loop and uv-detector was employed. Individual chromatographic conditions are shown in Table II. FT-NMR spectra were recorded on a JEOL GSX400 spectrometer with a 5-mm broadband probe at ambient temperature. ${ }^{13} \mathrm{C}$ spectra were ${ }^{1} \mathrm{H}$-decoupled. Resonances reported are relative to the solvent $\mathrm{d}^{6}$-benzene.

\section{Results and Discussion}

Like dimethylnitramine (DMN) and diisopropylnitramine (DIPN), all the nitramines in solution or in the neat melt decomposed with first-order kinetics. Rate constants at $240^{\circ} \mathrm{C}$, as well as activation energies are given in Table I. For three nitramines, diethylnitramine (DEN), 1,3dinitro-1,3-diazacyclohexane (mDNP), and RDX, thermolysis rates were compared in benzene and in $\mathrm{d}^{6}$-benzene. As was the case for DMN and DIPN, no solvent deuterium kinetic isotope effect (DKIE) was observed, supporting the hypothesis that in the decomposition of these nitramines intermolecular hydrogen transfer is not important. However, it should be noted that in the case of RDX, this result disagrees with a previous report. ${ }^{13}$ Although deuterated analogues were not prepared for each of the nitramines in this study, we observed a primary DKIE in $\mathrm{d}^{6} \mathrm{DMN}(1.56)$ and a primary DKIE has been reported for both RDX and HMX. ${ }^{14,15}$ From these kinetic results, we postulated that like DMN, other nitramines have a decomposition mode involving intramolecular hydrogen transfer. However, in the case of DMN decomposition, hydrogen transfer produced only gaseous products; this result would not be expected in more complex nitramines.

In the thermal decomposition of dimethylnitramine about half a mole of gas was formed per mole nitramine; this was attributed primarily to products arising from the intramolecular hydrogen transfer route. The only condensed phase product was dimethylnitrosamine, formed in over $80 \%$ yield. ${ }^{2}$ The nitrosamine was assumed to arise from $\mathrm{N}-\mathrm{NO}_{2}$ homolysis. Examining the condensedphase species remaining from the thermolysis of mixed ${ }^{15} \mathrm{~N}-{ }^{15} \mathrm{~N}$ labeled dimethylnitramine with unlabeled dimethylnitramine, we observed complete label scrambling in dimethylnitrosamine, in agreement with similar results of Suryanarayana and Bulusu. ${ }^{16}$ However, in contrast to their findings, we also observed a limited amount of label scrambling in the reactant nitramine. ${ }^{2}$

To determine if the mechanism suggested for DMN applied to more complex nitramines, 
the thermal decomposition products of a series of acyclic nitramines [diethylnitramine (DEN), dipropylnitramine (DPN), and diisopropylnitramine (DIPN)] were examined. All formed about a half mole of gas per mole of nitramine, and for all, except DIPN, the only condensed-phase product was the corresponding nitrosamine. For DIPN, the proposed hydrogen transfer decomposition route should have produced nitrogen gas, isopropanol, and acetone. Thermolysis of DIPN produced $\mathrm{N}_{2}$, diisopropylnitrosamine, and acetone in roughly a one-to-one-to-two ratio. Although no isopropanol was detected in DIPN thermolysis, it was argued that under the reaction conditions isopropanol would be oxidized to acetone. Therefore, this additional condensed-phase product (acetone) found in DIPN thermolysis is accounted for by intramolecular hydrogen transfer. ${ }^{2}$ However, it should be noted that the decomposition of DIPN produced some propane and other unaccounted for condensed-phase species; furthermore, the thermolysis of diisopropylnitramine was significantly faster than that of the other acyclic nitramines. We interpret these results as an indication that as the hydrocarbon substituent on the nitramine becomes more complex, the number of available reaction paths increase. In fact, among the acyclic nitramines, the rate of decomposition increased as the carbon chain length increased, indicating the importance of the degree of substitution on the carbon attached to the amine nitrogen.

GC/MS analysis was used to identify the condensed-phase products of cyclic mononitramines [N-nitropiperidine (NPIP) and N-nitropyrrolidine (NPyr)], cyclic dinitramines [N-dinitropiperazine (pDNP), 1,3-dinitro-1,3-diazacyclopentane (DNI), and 1,3-dinitro-1,3diazacyclohexane (mDNP)], and 1,3,5-trinitro-1,3,5-triazocyclohexane (RDX) and 1,3,3trinitroazetidine (TNAZ). Allthese nitraminesproduced nitrosamines; in fact only in the case of RDX were they not the principal products. Those compounds with more than one nitramine functionality showed evidence of sequential conversion of nitro to nitroso. For NPIP, NPyr, and mDNP nitroso compounds were the only condensed-phase products. For dinitropiperazine (pDNP), piperazine itself was also identified by comparison to an authentic sample. Thermolysis products of TNAZ, other than the N-nitroso, will be discussed elsewhere. ${ }^{17}$ For 1,3-dinitro-1,3diazacyclopentane (DNI) the fragmentation pattern was not definitive for the nitrosamines, but they were inferred from the large peak at $\mathrm{m} / \mathrm{e} 30$ and from their retention times; the ${ }^{13} \mathrm{C}$ NMR suggested there may be at least one other condensed-phase product. RDX thermolyzed in benzene to about $40 \%$ decomposition produced GC peaks identified by comparison with the GC/MS patterns of authentic samples as the mono-, di-, and tri-nitroso species. After that time, these species disappeared leaving numerous uncharacterized species. Nitrosamines have also been observed in the residue of drop-weight impact studies on $\mathrm{RDX}^{18}$ and in the residue of burned RDX propellant. ${ }^{19}$ In a label scrambling test similar to that we conducted with $\mathrm{DMN},{ }^{2} \mathrm{RDX}$ was heated under an ${ }^{15} \mathrm{NO}_{2}$ atmosphere. The time of heating had to be shortened to prevent complete decomposition of the RDX since $\mathrm{NO}_{2}$ accelerated its decomposition, as it did the decomposition of DMN. Although the GC/MS spectrum was unclear as to whether any nitrosamine products were produced, the lack of incorporation of the ${ }^{15} \mathrm{~N}$ label in the starting material is in line with what was observed for DMN.

Among the cyclic nitramines, it was observed that the presence of more than one nitramine functionality in the ring enhanced decomposition (Table I). The two mononitramines Nnitropiperidine (NPIP) and N-nitropyrrolidine (NPyr) decomposed more slowly than the dinitramines, dinitropiperazine (mDNP) and 1,3-dinitro-1,3-diazacyclohexane (pDNP). A 
dramatic increase in decomposition rate was observed when the dinitramine functionalities were meta to each other, as in 1,3-dinitro-1,3-diazacyclopentane (DNI) and 1,3-dinitro-1,3diazacyclohexane (pDNP), rather than para, as in dinitropiperazine.

Therefore, it is not surprising that RDX, HMX, and HNIW are among the least thermally stable nitramines studied. Ring strain or perhaps bonding angle around the amine nitrogen ${ }^{20}$ appears to play a role in increasing the rate of thermal decomposition since 1,3-dinitro-1,3-diazacyclohexane (mDNP) decomposes much more slowly than 1,3-dinitro-1,3-diazacyclopentane (DNI) and HMX decomposes more slowly than RDX.

Although the $240^{\circ} \mathrm{C}$ decomposition rate constants differ considerably for acyclic, cyclic, and multifunctional nitramines, all the observed decompositions, in solution or neat, were firstorder with activation energies in the range of 40 to $50 \mathrm{kcal} / \mathrm{mol}$. Furthermore, these activation energies differ little from the corresponding ones measured in the neat condensed-phase decomposition (Table I). Since the presence or absence of solvent had little effect of the activation energy and deuteration of the solvent had no effect on the rate constant, the decomposition mechanism being probed must be unimolecular. The retarding effect of increased solvent viscosity, ${ }^{2}$ the positiveactivation volume, ${ }^{2,21}$ the common observation of nitrosamines, and the fact that this diverse group of nitramines all exhibited activation energies similar in magnitude to the N$\mathrm{NO}_{2}$ bond energy suggest a common rate-determining step in the decomposition. The most logical common step is $\mathrm{N}-\mathrm{NO}_{2}$ bond scission.

Having focused on the similarities in the decomposition of various nitramines, we must also acknowledge the differences. Although the activation energies among the nitramines are of similar magnitude, the rates of decomposition vary over a 100 -fold range (compared at $240^{\circ} \mathrm{C}$, Table I). RDX, DNI (1,3-dinitro-1,3-diazacyclopentane), and HNIW (hexanitrohexaazaisowurzitane) were the most thermally unstable nitramines. HNIW was so unstable that the highest temperature that could be studied readily was $226^{\circ} \mathrm{C}$ rather than $240^{\circ} \mathrm{C}$. This difference in thermal stability undoubtly arises from the decomposition pathways available subsequent to N-N bond homolysis. The number and accessibility of these subsequent routes to decomposition depend on the other structural features in the molecule.

Thermolysis of mixed ${ }^{15} \mathrm{~N}-{ }^{15} \mathrm{~N}$ labeled dimethylnitramine with unlabeled dimethylnitramine yielded nitrogen with complete label scrambling. This is in line with the proposed intramolecular hydrogen transfer, which is the source of the internal DKIE. However, this result is in contrast to those observed when ${ }^{15} \mathrm{NO}_{2}$-labeled HMX was examined: all $\mathrm{N}_{2}$ and $\mathrm{N}_{2} \mathrm{O}$ contained one labeled and one unlabeled nitrogen, and NO was exclusively ${ }^{15} \mathrm{~N}$ labeled. ${ }^{22}$ ) The composition of the gaseous decomposition products for all the examined nitramines is shown in Table III. RDX and HMX are unique among the nitramines studied in the large quantities of nitrous oxide produced. However, in solution phase decomposition, they behaved more like the other nitramines, with $\mathrm{N}_{2}$ by far the major nitrogen-containing gas. Probing for the source of this difference we examined the decomposition products of RDX. Upon complete decomposition, neat RDX produced primarily 
gases, but some unidentified condensed products were alsoformed. In contrast, when the solution phase thermolysis of RDX was about $40 \%$ complete, it was possible to identify the mono-, di- and tri- nitrosamines decomposition products by comparison of their GC/MS pattern with authentic samples.

Curious about possible differences in solution, vapor, and condensed-phase thermolyses, we examined the decomposition of $\mathrm{RDX}$ at $240^{\circ} \mathrm{C}$ in each phase. Table IV compares the rate constants and the maximum amount of mono-nitroso RDX derivative formed and Table $\mathrm{V}$ the decomposition gases under each condition. The solution phase reaction accentuates the nitrosamine intermediate (Table IV). At about 71\% decomposition, RDX in solution showed about $24 \%$ of the mononitroso-product; at the same point in the decomposition in vapor phase, only about $6 \%$ of the mononitroso-product was detected. At the same time, Table V indicates substantially less gas but more $\mathrm{N}_{2}$ has been formed in the solution decomposition than in the vapor. Both the vapor and neat decomposition yielded about equal amounts of $\mathrm{N}_{2}$ and $\mathrm{N}_{2} \mathrm{O}$, while the solution decomposition produced almost no $\mathrm{N}_{2} \mathrm{O}$. Decomposition rate constants vary slightly in the various phases, but the variation in rate constants is minor compared to the variations in the products.

Understanding the difference in product distribution in the vapor and solution phase decompositions of RDX facilitates our understanding of other differences in their decomposition schemes. In all nitramines, the trigger linkage appears to be N-N homolysis. In solution decomposition, the amine radical is stabilized sufficiently so that it resists further decomposition and instead reacts with NO to form nitrosamine. However, in vapor or condensed phase decomposition, the amine radical undergoes further break down before the lost $\mathrm{NO}_{2}$ can return as the reduced NO; therefore, little nitrosamine is formed. In the case of RDX and HMX, the loss of only one $\mathrm{NO}_{2}$ group triggers the breakdown of the entire heterocycle. In monofunctional nitramines, N-N scission means the most likely fate of each nitrogen atom is formation of nitrogen gas. In RDX and HMX, once the first N-N bond is broken, the rest of the heterocycle can unravel, the extra nitramine functionalities forming nitrous oxide rather than nitrogen gas.

$$
\begin{aligned}
& \mathrm{HMX} \rightarrow \mathrm{NO}_{2}+\mathrm{HCN}+3 \mathrm{H}_{2} \mathrm{C}=\mathrm{N}-\mathrm{NO}_{2} \\
& \mathrm{H}_{2} \mathrm{C}=\mathrm{N}-\mathrm{NO}_{2} \rightarrow \mathrm{NNO}+\mathrm{H}_{2} \mathrm{CO}
\end{aligned}
$$

In solution, the decomposition gases are predominately dinitrogen, and more nitrosamine is observed because the amine radical remaining after initial $\mathrm{NO}_{2}$ loss is stabilized by the solvent, preventing further unraveling of the ring. This explains why previous labeling experiments with neat $\mathrm{HMX}^{22,23}$ and $\mathrm{RDX}^{24}$ showed no scrambling of label in the $\mathrm{N}_{2} \mathrm{O}$, while we observed label scrambling in all the nitrogen-containing decomposition gases of DMN. In DMN decomposition, nitrous oxide is a minor product. In the decomposition of RDX or HMX, it is a major product, but the production of nitrous oxide in these species is by an entirely different route than it is in DMN. It arises from the decomposition of $\mathrm{H}_{2} \mathrm{C}=\mathrm{N}_{-} \mathrm{NO}_{2}$, resulting from the unraveling of the heterocyclic ring.

\section{Conclusions}

For dimethylnitramine (DMN) two decomposition routes are postulated: hydrogen transfer 
from the methyl group of the nitramine to the $\mathrm{NO}_{2}$ group resulting in loss of $\mathrm{HONO}$; and $\mathrm{N}$ $\mathrm{NO}_{2}$ homolysis. The first route would be first order and explain the ${ }^{15} \mathrm{~N}$ label scrambling in the nitrogen gases and the internal DKIE. The second would be a first-order route to nitrosamine and would explain the solvent cage effect and positive activation volume. ${ }^{2}$

As the nitramines become more complex than $\mathrm{DMN}$, the rate of decomposition increases and the product distribution is more complex. As the length of the aliphatic chain increases in acyclic nitramines, the rate of thermolysis increases, yet nitrosamine remains the only condensedphase product. When a secondary carbon is attached to the N-nitramine (DIPN) rather than primary (DPN), the rate of decomposition increases and a new condensed-phase product is formed. Among the cyclic nitramines, the rate of decomposition increases as the number of $\mathrm{NNO}_{2}$ groups increase. The position of the nitramine groups affects the decomposition; meta $\mathrm{NNO}_{2}$ groups decompose faster than para. Ring strain decreases or the angle around nitrogen changes.

The increase in decomposition rate, the appearance of new products, and the change in the relative importance of nitrosamine and of $\mathrm{N}_{2}$ and $\mathrm{N}_{2} \mathrm{O}$ is due to new decomposition routes available to complex nitramines. However, since complex nitramines (e.g. RDX) maintain first-order kinetics and an internal DKIE and produce nitrosamines and since most have activation energies in the range of 40 to $50 \mathrm{kcal} / \mathrm{mol}$, it is believed that the triggering mechanism remains $\mathrm{N}-\mathrm{NO}_{2}$ homolysis. In solution thermolyses of the reactant nitramines, the intermediate amine radical is stabilized, thus, promoting nitrosamine formation and suppressing autocatalytic behavior. In the condensed or vapor phase thermolysis of nitramines with alternating nitramine functionalities, such as RDX and HMX, initial loss of $\mathrm{NO}_{2}$ triggers the unraveling of the heterocyclic ring. Furthermore, there is evidence that intramolecular hydrogen transfer, postulated for DMN, is also important in more complex nitramines and could act as an alternate trigger for ring dissociation.

\section{Acknowledgments}

We are grateful to the Office of Naval Research for their support of this work through Grant No.: \#N00014-89-J-3143.

\section{References}

1. Taken in part from the theses work of Rick Szeckeres and Weiyi Zheng; New Mexico Institute of Mining \& Technology.

2. Oxley, J.C. Hiskey, M.A., Naud, D.; Szekeres, R. J. Phys. Chem. 1992, 96, 2505-2509.

3. Cosgrove, J.D.; Owens , A.J. Combust. Flame 1974, 22, 13.

Cosgrove, J.D.; Owens , A.J. Combust. Flame 1974, 22, 19.

4. Batten, J.J. Aust. J. Chem., 1970, 24, 945 \& 1971, 24, 2025.

5. Chute, W.J.; Herring, K.G.; Toombs, L.E.; Wright, G.F.

Can J. Res.1947, 26, 89-103.

6. Robson, J.H.; Reinhart, J. J. Am. Chem. Soc., 1955, 77, 2453-2457. Robson, J.H. J. Am. 
Chem. Soc., 1955, 77, 107-108.

7. $\quad$ Emmons, W.D.; Pagano, A.S.; Stevens, T.E. J. Org. Chem., 1958, 23, 311-313.

8. Gruenhut, N.S.; Goldfrank, M.; Cushing, M.L; Caesar "20. Nitrogen Oxide", Inorg. Syn. Ed. p 78-81.

9. Goodman, L. J. Am. Chem. Soc., 1953, 75, 3019.

10. Blatt, H.H. Org. Syn. Blatt, A.H. Ed., Wiley, 1943, p 211.

11. Bell, J.A.; Dunstan, I. J. Chem. Soc. (C) 1969, 1556 and 1559.

12. Bonner, T.G.; Hancock, R.A.; Roberts, J.C. J.C.S. Perkin II 1974, 653. Brockman, F.J.;

Downing, D.C.; Wright G.F. Can. J. Res. 1949, $27(B), 469$.

13. Hoffsommer, J.C.; Glover, D.J. Combust. Flame 1985, 59303.

14. Hoffsommer, J.C.; Glover, D.J.; Kubose, D.A. J. Phys. Chem. 1977, 81, 380. Hoffsommer, J.C.; Carlson, D.W. Combust. Flame 1987.

15. Bulusu, S. Weinstein, D.I., Autera, J. R., Velicky, R.W. J. Phys.

Chem. 1986, 90, 4121.

Shackelford, S.A.; Coolidge, M.B.; Goshgarian, B.B.; Loving, B.A.;

Rogers, R.N.; Janney, J.L.; Ebinger, M.H. J. Phys. Chem. 1985, 89, 3118.

16. Suryanarayanan, K.; Bulusu, S. J. Phys. Chem. 1972, 76, 496.

17. TNAZ manuscript in preparation.

18. Hoffsommer, J.C.; Glover, D.J.; Elban, W.L. J. Energetic Mat. 1985, 3, 149-167.

19. Schroeder, M.A.; Fifer, R.A.; Miller, M.S.;Pesce-Rodriguez,R.A.; Singh, G. "Condensed-Phase Processes During Solid Propellant Combustion. Part II: Chemical and Microscopic Examination of Conductively Quenched Samples of RDX, XM39, JA2, M30, and HMX-Binder Compositions" BRL-TR-3337, May 1992.

20. Burov, Yu. M.; Nazin, G.M. Kinetika i Kataliz 1982, 23, 12; translation pages 5-10.

21. Piermarini, G.J.; Block, S.; Miller, P.J. J. Phys. Chem 1989, 93, 462-466 and J. Phys. Chem 1987, 91, 3872-3878.

22. Suryanarayana,B.; Graybush,R.J.; Autera,J.R. Chem. Ind. 1967, 2177.

23. Behrens, R. J. Phys. Chem 1990, 94, 6706. 
Behrens, R.; Bulusu, S. J. Phys. Chem 1991, 95, 5838-5845.

24. Behrens, R.; Bulusu, S. J. Phys. Chem 1992, 96, 8877-8891. Behrens, R.; Bulusu, S. J. Phys. Chem 1992, 96, 8891-8897. 
Table I

Kinetic Parameters of Nitramine Decomposition

\begin{tabular}{|c|c|c|c|c|c|c|c|c|}
\hline Sample & $\begin{array}{l}\text { No. } \\
\text { dat }\end{array}$ & $\begin{array}{l}\text { Temp Range } \\
\text { a }\left({ }^{\circ} \mathrm{C}\right)\end{array}$ & $\begin{array}{c}\begin{array}{c}\mathrm{Ea} \\
\mathrm{kcal}\end{array} \\
\mathrm{mol}\end{array}$ & $\frac{\mathrm{kJ}}{\mathrm{mol}}$ & $\begin{array}{l}A \\
S^{-1}\end{array}$ & Solvent & $\begin{array}{r}\text { Conc. } \\
\text { at }\end{array}$ & $\begin{array}{l}\text { Rate } \\
\text { Constant } \\
\text { t } 240^{\circ} \mathrm{C}\end{array}$ \\
\hline $\mathrm{DMN}$ & $\begin{array}{l}6 \\
6\end{array}$ & $\begin{array}{l}200-300 \\
200-280\end{array}$ & $\begin{array}{l}46.7 \\
38.0\end{array}$ & $\begin{array}{l}195 \\
159\end{array}$ & $\begin{array}{l}6.72 \mathrm{E}+17 \\
1.72 \mathrm{E}+13\end{array}$ & isooctane & $\begin{array}{l}.1 \% \\
\text { neat }\end{array}$ & $\begin{array}{l}\text { 9. } 0 E-04 \\
1.0 E-03\end{array}$ \\
\hline $\mathrm{DEN}$ & 6 & $200-300$ & 45.1 & 189 & $1.81 E+16$ & isooctane & $.1 \%$ & 1.2E-03 \\
\hline $\mathrm{DPN}$ & 3 & $220-260$ & 48.0 & 201 & 4. $40 \mathrm{E}+17$ & isooctane & $.1 \%$ & $2.0 E-03$ \\
\hline DIPN & $\begin{array}{l}6 \\
3\end{array}$ & $\begin{array}{l}200-300 \\
220-250\end{array}$ & $\begin{array}{l}42.6 \\
43.9\end{array}$ & $\begin{array}{l}178 \\
184\end{array}$ & $\begin{array}{l}8.80 \mathrm{E}+15 \\
1.38 \mathrm{E}+16\end{array}$ & $\begin{array}{c}\text { isooctane } \\
\text { acetone }\end{array}$ & $\begin{array}{l}.1 \% \\
.7 \%\end{array}$ & $\begin{array}{l}6.2 E-03 \\
2.9 E-03\end{array}$ \\
\hline NPIP & $\begin{array}{l}5 \\
5\end{array}$ & $\begin{array}{l}220-300 \\
240-290\end{array}$ & $\begin{array}{l}48.2 \\
47.5\end{array}$ & $\begin{array}{l}202 \\
199\end{array}$ & $\begin{array}{l}4.42 E+16 \\
2.07 E+16\end{array}$ & $\begin{array}{l}\text { benzene } \\
\text { acetone }\end{array}$ & $\begin{array}{l}10 \% \\
.7 \%\end{array}$ & $\begin{array}{l}6.5 E-04 \\
1.2 E-04\end{array}$ \\
\hline $\mathrm{NP}$ & 5 & $240-290$ & 51.5 & 215 & $2.87 E+18$ & acetone & $.7 \%$ & 3. $0 E-04$ \\
\hline $\mathrm{pDNP}$ & 5 & $220-280$ & 52.6 & 220 & $1.23 E+19$ & acetone & $.9 \%$ & $5.4 \mathrm{E}-04$ \\
\hline $\mathrm{mDNP}$ & $\begin{array}{l}5 \\
6 \\
3\end{array}$ & $\begin{array}{l}200-280 \\
200-300 \\
240-260\end{array}$ & $\begin{array}{l}49.1 \\
40.0 \\
41.9\end{array}$ & $\begin{array}{l}205 \\
167 \\
175\end{array}$ & $\begin{array}{l}9.40 \mathrm{E}+17 \\
4.00 \mathrm{E}+14 \\
2.53 \mathrm{E}+15\end{array}$ & $\begin{array}{l}\text { acetone } \\
\text { ethanol }\end{array}$ & $\begin{array}{l}.9 \% \\
\text { neat }\end{array}$ & $\begin{array}{l}4.7 E-03 \\
3.5 E-03\end{array}$ \\
\hline TNAZ & $\begin{array}{l}4 \\
3\end{array}$ & $\begin{array}{l}189-263 \\
220-250\end{array}$ & $\begin{array}{l}43.6 \\
43.7\end{array}$ & $\begin{array}{l}182 \\
183\end{array}$ & $\begin{array}{l}2.80 \mathrm{E}+16 \\
1.85 \mathrm{E}+16\end{array}$ & acetone & $\begin{array}{l}.7 \% \\
\text { neat }\end{array}$ & $\begin{array}{l}\text { 8. } 3 E-03 \\
4.6 E-03\end{array}$ \\
\hline HMX & $\begin{array}{l}6 \\
4\end{array}$ & $\begin{array}{l}189-289 \\
230-270\end{array}$ & $\begin{array}{l}50.2 \\
52.9\end{array}$ & $\begin{array}{l}210 \\
221\end{array}$ & $\begin{array}{l}8.28 \mathrm{E}+18 \\
2.46 \mathrm{E}+18\end{array}$ & acetone & $\begin{array}{l}1 \% \\
\text { neat }\end{array}$ & $2.5 E-03$ \\
\hline DNI & $\begin{array}{l}5 \\
4\end{array}$ & $\begin{array}{l}200-240 \\
200-250\end{array}$ & $\begin{array}{l}47.8 \\
47.2\end{array}$ & $\begin{array}{l}200 \\
197\end{array}$ & $\begin{array}{l}1.27 \mathrm{E}+19 \\
4.92 \mathrm{E}+18\end{array}$ & acetone & $\begin{array}{l}\text { 9\% } \\
\text { neat }\end{array}$ & $\begin{array}{l}2.7 E-02 \\
3.4 E-02\end{array}$ \\
\hline RDX & $\begin{array}{l}3 \\
6 \\
4\end{array}$ & $\begin{array}{l}200-240 \\
206-256 \\
200-250\end{array}$ & $\begin{array}{l}45.4 \\
38.5 \\
37.8\end{array}$ & $\begin{array}{l}190 \\
161 \\
158\end{array}$ & $\begin{array}{l}7.40 \mathrm{E}+17 \\
1.39 \mathrm{E}+14 \\
1.99 \mathrm{E}+14\end{array}$ & $\begin{array}{l}\text { acetone } \\
\text { benzene }\end{array}$ & $\begin{array}{l}.7 \% \\
.9 \% \\
\text { neat }\end{array}$ & $\begin{array}{l}3.2 E-02 \\
1.7 E-02\end{array}$ \\
\hline HNIW & 6 & $146-226$ & 42.4 & 177 & 4. $0 E+17$ & acetone & $1 \%$ & $\begin{array}{l}\text { 8. } 8 \mathrm{E}-02^{\star} \\
\star \text { at } 226^{\circ} \mathrm{C}\end{array}$ \\
\hline $\begin{array}{l}\text { DMN } \\
\text { DEN } \\
\text { DIPN } \\
\text { mDNP } \\
\text { RDX }\end{array}$ & & $\begin{array}{r}\text { Rate } \\
\text { benzene } \\
2.7 E-04 \\
4.8 E-04 \\
4.1 E-03 \\
4.1 E-03 \\
1.1 E-03\end{array}$ & \multicolumn{2}{|c|}{ Constants } & $\begin{array}{l}\text { at } 240^{\circ} \mathrm{C} \\
\text { d } 6 \text { benze } \\
2.8 \mathrm{E}-04 \\
4.6 \mathrm{E}-04 \\
4.3 \mathrm{E}-03 \\
3.0 \mathrm{E}-03 \\
9.7 \mathrm{E}-04\end{array}$ & $\begin{array}{l}\text { ene } \\
4 \\
4 \\
3 \\
3 \\
4\end{array}$ & & \\
\hline
\end{tabular}


Table II

Chromatorgraphic Columns and Conditions for Nitramine Detection

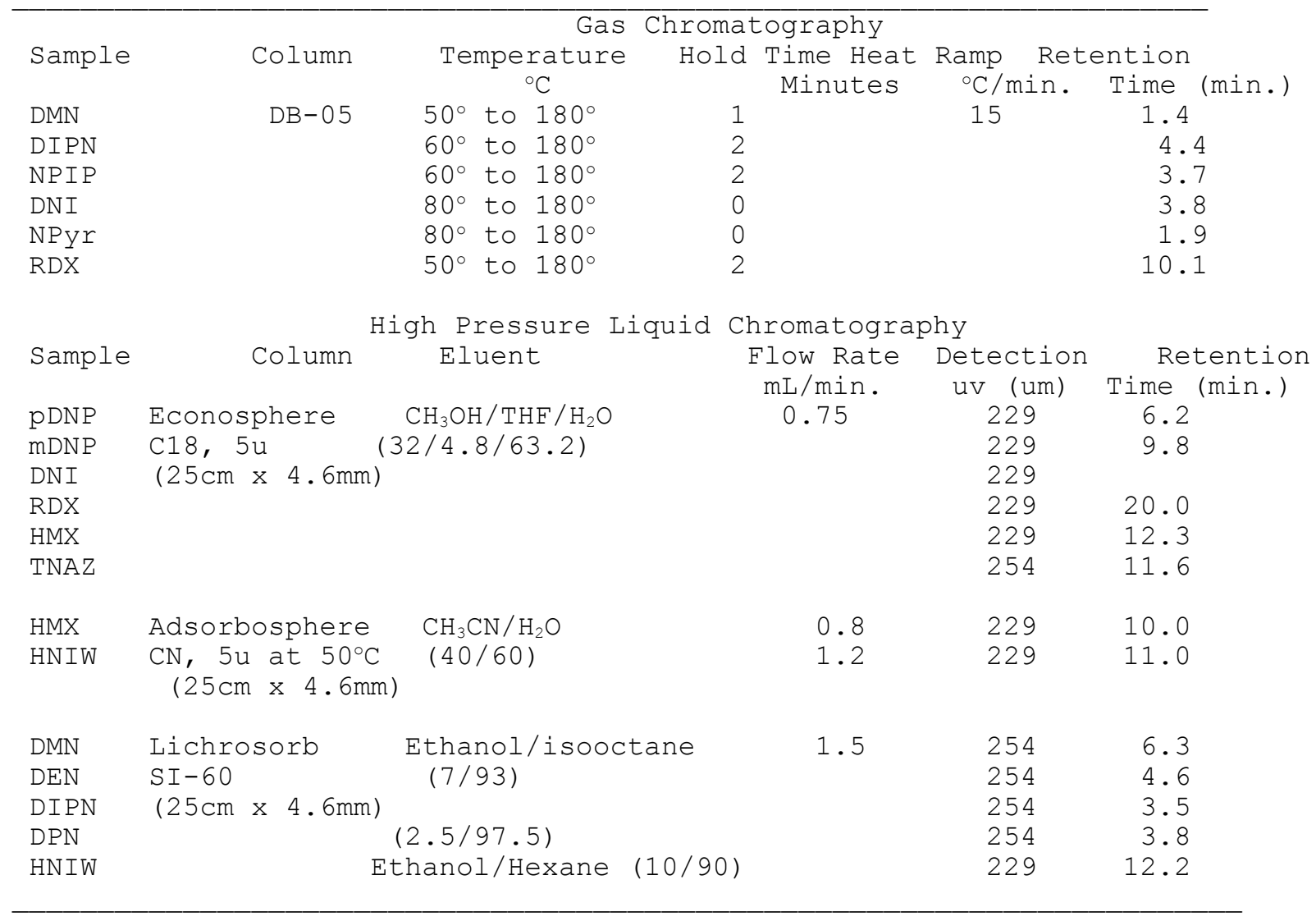

Table III

Moles of Gas per Mole Nitramine Heated at $240^{\circ} \mathrm{C}$ for $10 \mathrm{Half}$-Lives

\begin{tabular}{|c|c|c|c|c|c|c|c|c|c|c|c|}
\hline & \multicolumn{6}{|c|}{ Condensed-Phase Neat } & \multicolumn{5}{|c|}{ 1\% in Acetone } \\
\hline & $\mathrm{N}_{2}$ & $\mathrm{~N}_{2} \mathrm{O}$ & $\mathrm{CO}_{2}$ & $\mathrm{CO}$ & NO & Total & $\mathrm{N}_{2}$ & $\mathrm{~N}_{2} \mathrm{O}$ & $\mathrm{CO}_{2}$ & $\mathrm{CO}$ & Total \\
\hline DMN & 0.15 & 0.01 & 0.26 & 0.07 & & 0.49 & 0.02 & 0.00 & 0.07 & 0.07 & 0.15 \\
\hline DEN & 0.31 & 0.01 & 0.08 & 0.08 & & 0.48 & & & & & \\
\hline DPN & 0.29 & 0.03 & 0.06 & 0.08 & & 0.45 & & & & & \\
\hline $\mathrm{DIPN}$ * & 0.35 & 0.04 & 0.04 & 0.02 & & 0.45 & 0.15 & 0.01 & 0.02 & 0.04 & 0.23 \\
\hline NPIP & & & & & & & 0.07 & 0.02 & 0.06 & 0.04 & 0.19 \\
\hline NPyr & 0.19 & 0.07 & 0.17 & 0.04 & & 0.47 & 0.07 & 0.03 & 0.06 & 0.03 & 0.19 \\
\hline $\mathrm{pDNP}$ & 0.37 & 0.07 & 0.48 & 0.12 & & 1.04 & 0.26 & 0.05 & 0.12 & 0.17 & 0.60 \\
\hline $\mathrm{mDNP}$ & 1.13 & 0.25 & 0.98 & 0.43 & & 2.79 & 0.63 & 0.08 & 0.20 & 0.26 & 1.17 \\
\hline HMX & 0.82 & 2.81 & 1.20 & .61 & & 5.44 & 0.99 & 0.26 & 0.60 & 0.48 & 2.33 \\
\hline $\mathrm{DNI}$ & 1.18 & 0.15 & 0.77 & 0.27 & & 2.37 & 0.41 & 0.05 & 0.21 & 0.22 & 0.89 \\
\hline RDX & 1.37 & 1.24 & 0.86 & 0.88 & & 4.35 & 0.49 & 0.04 & 0.15 & 0.26 & 0.94 \\
\hline HNIW & 4.29 & 0.82 & 3.30 & 1.20 & & 9.61 & 0.97 & 0.07 & 0.20 & 0.19 & 1.43 \\
\hline TNAZ & 0.86 & 0.11 & 1.55 & 0.61 & 0.9 & 4.03 & 0.15 & 0.03 & 0.31 & 0.38 & 0.87 \\
\hline
\end{tabular}

* plus $0.1 \mathrm{~mol} / \mathrm{mol}$ propane 
Table IV

RDX Thermolysis

Maximum Moles of Mono-Nitroso Derivative Formed per Mole RDX

\begin{tabular}{|c|c|c|c|c|c|c|c|c|}
\hline & \multicolumn{3}{|c|}{$240^{\circ} \mathrm{C}$} & & & \multicolumn{3}{|c|}{$220^{\circ} \mathrm{C}$} \\
\hline & $\mathrm{NO}-\mathrm{RDX}$ & $\mathrm{k}$ & & \% decomp & $\mathrm{NO}-\mathrm{RDX}$ & $\mathrm{k}$ & & comp \\
\hline & $\mathrm{mol} / \mathrm{mol}$ & $\sec ^{-1}$ & sec & & $\mathrm{mol} / \mathrm{mol}$ & $\mathrm{sec}^{-1}$ & sec & \\
\hline acetone & 0.238 & 0.033 & 40 & 71 & 0.237 & 0.0071 & 180 & 73 \\
\hline neat & 0.059 & 0.014 & 40 & 44 & 0.046 & 0.0021 & 120 & 18 \\
\hline vapor & 0.061 & 0.017 & 70 & 71 & & & & \\
\hline
\end{tabular}

Table V

Moles of Gas Formed per Mole RDX Heated at $240^{\circ} \mathrm{C}$

\begin{tabular}{|c|c|c|c|c|c|c|c|c|}
\hline \multirow{3}{*}{$\begin{array}{l}\text { \% Decomposition } \\
\text { Seconds }\end{array}$} & \multicolumn{2}{|c|}{ in acetone } & \multicolumn{3}{|c|}{ neat } & \multicolumn{3}{|c|}{ vapor } \\
\hline & 100 & 70 & 100 & 70 & 30 & 100 & 70 & 30 \\
\hline & 211 & 37 & 481 & 83 & 25 & 397 & 69 & 21 \\
\hline $\mathrm{N}_{2}$ & 0.90 & 0.43 & 1.31 & 1.07 & 0.39 & 1.33 & 0.52 & 0.1 \\
\hline $\mathrm{N}_{2} \mathrm{O}$ & 0.09 & 0.03 & 1.18 & 0.81 & 0.13 & 1.09 & 0.59 & 0.0 \\
\hline $\mathrm{CO}_{2}$ & 0.26 & 0.08 & 0.72 & 0.44 & 0.13 & 0.60 & 0.21 & 0.0 \\
\hline $\mathrm{CO}$ & 0.28 & 0.03 & 0.74 & 0.58 & 0.22 & 0.53 & 0.21 & 0.3 \\
\hline Total & 1.53 & 0.57 & 3.95 & 2.90 & 0.87 & 3.55 & 1.53 & 0.60 \\
\hline
\end{tabular}

